\title{
STUDI EVALUATIF SISTEMI PEMBELAJARAN BAHASA ARAB DI MA PUTRA PONDOK MODERN DARUSSALAMI LIABUKU KOTA BAU BAU
}

\author{
Ahmad Talim \\ PPS UIN Alauddin Makassar \\ Samata-Gowa \\ Email: butony9@gmail.com
}

\begin{abstract}
The focus of this research is the Arabic learning system in MA Putra Bau Bau Darussalam Islamic Boarding School in Bau Bau City. From these problems, this study aims to evaluate the Arabic learning system in Darussalam Islamic Boarding School which is focused on the main issues, namely: 1) How is the compatibility of the Antasedent Arabic learning system entry in Darussalam Liabuku Bau Bau Islamic boarding school with the process standard?
\end{abstract}

This type of research is a program evaluation with a descriptive qualitative approach, in this study the authors assess the quality level and conditions of the Arabic language learning system in Darussalam Islamic Boarding School Liabuku Bau Bau. To obtain the data, three data collection techniques were used, namely observation, interviews and documentation. After data collection, the data processing is then processed through three stages, namely: 1) data reduction, 2) data display, 3) and drawing conclusions / verification.

The results of this study indicate that learning Arabic in MA Putra Darussalam Liabuku Islamic boarding school is fulfilled with 3 standard processes, namely: achieving the existing Arabic learning objectives, teachers in MA Kulliyatul Muallimin al-Islamiyah Darussalam Liabuku Islamic boarding school Bau Bau make I 'dad al-Tadrīs to support the existing Arabic teaching and learning activities, because all of his learning uses Arabic as the medium. In evaluating students 'theoretical or practical language skills, the teacher evaluates learning in

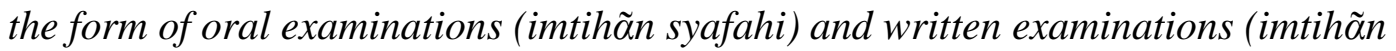
tahrīī), so that the assessment of students' Arabic Arabic abilities cannot be separated in the four language skills.

From this research, a strategic recommendation can be adopted in improving the learning system of KMI Pondok Modern Darussalam Liabuku, namely teachers working with Language Builders in language programs to improve the ability of the Santri Arabic language and provide a Language Laboratory to improve students' listening skills.

Keywords: Program Evaluation, Model Maintenance Count, KMI System. 


\section{PENDAHULUAN}

\section{A. Latar Belakang}

Dalam Pendidikan di Indonesia terdapat sistem yang mengatur berjalannya belajar mengajar dalam suatu lembaga pendidikan. Adapun sistem pendidikan yang ada yaitu mencakup beberapa hal, yaitu tujuan, materi, pendidik, peserta didik, metode dan evaluasi. Menurut Wina Sanjaya, Sistem adalah satu kesatuan komponen yang satu sama lain saling berkaitan dan saling berinteraksi untuk mencapai suatu hasil yang diharapkan secara optimal sesuai dengan tujuan yang telah ditetapkan. ${ }^{1}$

Sistem pembelajaran pada dasarnya merupakan cara-cara untuk mencapai tujuan pembelajaran yaitu tercapainya hasil belajar secara maksimal oleh peserta didik dalam kegiatan belajar. Pembelajaran bahasa Arab merupakan suatu sistem yang kompleks terdiri dari rangkaian komponen yang saling berkaitan, istilah sistem meliputi sebuah spectrum yang sangat luas dan memiliki komponen-komponen tertentu yang berfungsi untuk mencapai tujuan tertentu. ${ }^{2}$

Secara teoritis, keberhasilan pelaksanaan sistem pembelajaran merupakan kerja kooperatif dari beberapa komponen yang berjalan secara sistemik. Beberapa komponen tersebut tidak bisa dihilangkan salah satunya, sebab akan mengurangi sekaligus menghambat keberhasilan pembelajaran itu sendiri.

Komponen-komponen yang dimaksud adalah kematangan tujuan yang hendak dicapai, materi yang hendak diajarkan, adanya pendidik, peserta didik, strategi, media, sumber belajar, dan evaluasi yang hendak digunakan ${ }^{3}$ atau sebagaimana disebut oleh Sulistryorini setidak-tidaknya komponen dimaksud terdiri dari hubungan triangulasi dari tujuan, kegiatan dan evaluasi. ${ }^{4}$

Evaluasi tidak dapat dipisahkan dari pembelajaran karena efektifitas pembelajaran hanya dapat diketahui melalui evaluasi. Dengan kata lain melalui evaluasi semua komponen program pembelajaran dapat diketahui apakah berfungsi sebagaimana mestinya atau tidak. Pendidik dapat mengetahui tingkat kemampuan peserta didik baik secara kelompok maupun perseorangan. Menurut Ralph Tyler dalam Suharsimi Arikunto menyatakan bahwa evaluasi merupakan sebuah proses pengumpulan data untuk menentukan sejauh mana, dalam hal apa, dan bagaimana tujuan sudah tercapai. ${ }^{5}$

\footnotetext{
${ }^{1}$ Wina Sanjaya, Strategi Pembelajaran Berorientasi Standar Proses Pendidikan, (Cet. VIII, Jakarta : Kencana, 2011), h. 49.

${ }^{2}$ Wina Sanjaya, Perencanaan dan Desain Sistem Pembelajaran, (Jakarta : Kecana, 2008), h.1.

${ }^{3}$ Slamto, Belajar dan Faktor-faktor yang Mempengaruhinya, (Jakarta : Rineka Cipta, 2010), h.25.

${ }^{4}$ Sulistyorini, Evaluasi Pendidikan, (Yogyakarta: Teras, 2009), h.77.

${ }^{5}$ Suharsismi Arikunto, Dasar-dasar Evaluasi Pendidikan, (Jakarta : PT. Bumi Aksara, 2012), h.3.
} 
Pembelajaran bahasa Arab di Indonesia telah dilakukan di lembaga-lembaga pendidikan Islam, salah satunya pondok pesantren. Pesantren dalam struktur pendidikan nasional, merupakan mata rantai pendidikan yang sangat penting. Hal ini tidak hanya karena sejarah kemunculannya yang relatif lama, melainkan pesantren telah secara signifikan ikut andil dalam mencerdaskan kehidupan bangsa.

Selain problem metodologi, masalah linguistik juga menjadi salah satu problem pengajaran bahasa Arab di Indonesia. Perbedaan antara bahasa Arab dan bahasa Indonesia jelas menimbulkan masalah bagi siswa Indonesia dalam mempelajari bahasa Arab. Sebaliknya, semakin banyak aspek persamaan antara bahasa Indonesia dengan bahasa Arab akan mempermudah siswa Indoenesia dalam mempelajari bahasa Arab. Problem linguistik pada dasarnya merupakan hambatan yang terjadi dalam pengajaran bahasa Arab yang disebabkan karena perbedaan karakteristik internal linguistik bahasa itu sendiri. ${ }^{6}$

Tujuan utama dalam pembelajaran bahasa adalah penguasaan terhadap fungsi bahasa itu sendiri yaitu sebagai alat komunikasi, baik lisan maupun tulisan. Hal tersebut juga menjadi tujuan pembelajaran bahasa Arab bagi non-Arab, yaitu pencapaian kompetensi berbahasa Arab baik secara teoritas maupun praktis. ${ }^{7}$

Dalam pencapaian tujuan tersebut setiap pesantren akan menggunakan metode pembelajaran bahasa Arab yang sesuai dengan keadaan siswa juga dengan materi yang akan diberikan. Oleh sebab itu perlu dicari solusi yang tepat dalam rangka meningkatkan kualitas pembelajaran bahasa Arab, yang masih dianggap sulit oleh sebagian siswa. Salah satu yang dapat dilakukan adalah berusaha mencari metode-metode yang paling tepat dalam mengajarkan bahasa Arab agar siswa dapat lebih mudah mengerti dan memahaminya. Disamping itu, guru harus bisa mengemas pembelajaran bahasa Arab sedemikian rupa agar tercipta sikap dan motivasi pada diri siswa dalam mempelajari bahasa Arab.

Istilah pesantren atau pondok pesantren telah dibukukan dalam peraturan nomor 44 tahun 2007 tentang pendidikan agama dan keagamaan pasal 1 ayat 4 yang menyebutkan, bahwa pesantren atau pondok pesantren adalah Lembaga Pendidikan Keagamaan Islam berbasis masyarakat yang menyelenggarakan pendidikan diniyah atau secara terpadu dengan pendidikan lainnya. ${ }^{8}$

Berdasarkan riset awal bahasa Arab menjadi persoalan krusial di lingkungan pondok pesantren, karena persoalan bahasa Arab menjadi hambatan tersendiri dalam penguasaan khazanah pesantren. Bahasa Arab di lingkungan pesantren menjadi bahasa primer yang tidak boleh tidak dikuasai para santri, bahasa Arab sebagai bahasa primer

${ }^{6}$ Syamsuddin Asyrofi, Metodologi Pengajaran Bahasa Arab, h.56.

${ }^{7}$ Suja'I, Inovasi Pembelajaran Bahasa Arab, (Semarang : Wali Songo Press, 2008), h.3.

${ }^{8}$ Andri Lundeto, Sistem Pendidikan Pesantren : Analisis Masalah dan Solusi, (Malang : UIN Malang, 2012), h.1. 
didasarkan karena hampir seluruh referensi yang digeluti para santri menggunakan bahasa Arab di pesantren, pendidikan bahasa ini sejak dini diajarkan pada santri. ${ }^{9}$ Namun, meskipun bahasa Arab diajarkan sejak dini, bahasa Arab belum sepenuhnya dikuasai oleh santri. Hambatan yang paling nyata dari belum optimalnya kemampuan bahasa Arab, baik oral maupun tulisan di pesantren adalah akibat sistem pembelajaran.

Pondok Pesantren Darussalam Liabuku membagi pembelajaran bahasa Arab dalam

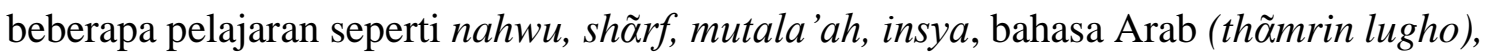
imlã, mahfuzat, balagah dan khõt, sehingga santri diajarkan bahasa Arab yang bersifat praktis. Santri menerima pembelajaran bahasa Arab dan langsung mempraktekannya dalam keseharian mereka.

Pondok Pesantren Darussalam Liabuku pula membentuk lingkungan bahasa atau bi'ah lugawiyyah dan menanamkan z $\tilde{\alpha} u q$ al-lugawi di kalangan para santri. Sehingga para santri lebih mengusasi muhadasah ketimbang memperhatikan kaidah bahasa Arab. Dalam berkomunikasi dengan bahasa Arab, terkadang santri menggunakan bahasa yang belum sesuai dengan kaidah bahasa Arab, sehingga memunculkan interferensi bahasa.

Berdasarkan uraian tentang masalah dalam bahasa Arab produktif tetap perlu memperhatikan kaidah-kaidah bahasa yang menopang terbangunnya bahasa yang baik dan benar, maka diperlukan evaluasi terhadap sistem pembelajaran bahasa Arab di Pondok Darussalam Liabuku Kota Bau Bau.

Fokus penelitan ini adalah sistem pembelajaran bahasa Arab di MA Putra Pondok Pesantren Darussalam Liabuku Kota Bau Bau. Dari permasalahan tersebut, penelitian ini bertujuan untuk mengevaluasi sistem pembelajaran bahasa Arab di Pondok Pesantren Darussalam yang difokuskan tiga pokok masalah, yaitu : 1) Bagaimana kesesuaian masuk Antasedent sistem pembelajaran bahasa Arab di pondok pesantren Darussalam Liabuku Bau Bau dengan standar proses?

\section{B. Tujuan Penelitian}

Untuk menganalisa pelaksanaan sistem pembelajaran bahasa Arab di MA Pondok Pesantren Darussalam Liabuku Bau Bau.

\section{KAJIAN TEORI}

\section{A. Konsep Evaluasi Program}

Dalam kamus Besar Bahasa Indonesia, kata evaluasi disamakan dengan penilaian. Sedangkan dalam kamus Oxford Advanced Learner's Dictionary, kata evaluate diartikan dengan : to form opinion of the amount, value or quality of something after thinking about it curefully. Definisi ini menyatakan bahwa evaluasi merupakan usaha memetakan nilai, jumlah ataupun kualitas dari sesuatu. Usaha ini harus dilakukan dengan hati-hati dan

\footnotetext{
${ }^{9}$ Amin Haedani, Masa Depan Pesantren : Tantangan Modernitas dan Tantangan Komplesitas
} Global, (Jakarta: IRD Press, 2010), h. 139-140. 
teliti. Sementara itu, Worthen dan Sanders menyatakan evaluasi adalah proses pengumpulan informasi untuk membantu mengambil keputusan. ${ }^{10}$ Menurut Gronlund dalam Djali, Evaluasi adalah suatu proses sistematis untuk menentukan dan membuat keputusan sampai sejauh mana tujuan program telah tercapai. ${ }^{11}$ Evaluasi yang berhubungan dengan pendidikan memberikan pengertian lebih lengkap, yaitu evaluasi pendidikan adalah penaksiran terhadap pertumbuhan dan kemajuan siswa kearah tujuan atau nilai-nilai yang telah ditetapkan dalam kurikulum. Proses menilai sesuatu berdasarkan kriteria atau tujuan yang telah ditetapkan yang selanjutnya diikuti dengan pengambilan keputusan atas objek yang dievalusi.

Rutman berpendapat bahwa evaluasi program adalah suatu kegiatan yang membutuhkan metode ilmiah untuk mengukur implementasi dan hasil program dengan tujuan untuk membuat keputusan. ${ }^{12}$

Sependapat dengan Rutman, Langbein dan Felbinger menyatakan :

Program evaluation is the application of emprical social science research methods to the process of judging the effectiveness of public policies, programs, or projects, as well as their management and implementation, for decision-making purposes. ${ }^{13}$

Makna evaluasi dalam definisi ini merupakan bagian dari metode penelitian sosial meliputi proses pengambilan keputusan mengenai efektifitas pengelolaan dan pelaksanaan program untuk kepentingan pengambilan keputusan.

Berdasarkan pengertian evaluasi program di atas menunjukkan bahwa evaluasi program adalah serangkaian kegiatan sistematis untuk mengumpulkan data dan informasi sebagai masukan untuk pengambilan keputusan terhadap program yang dievaluasi. Dengan demikian, evaluasi program mengandung tiga unsur penting, yaitu 1) kegiatan sistematis, 2) pengumpulan data dan informasi, dan 3) masukan untuk pengambilan keputusan terhadap program.

Kegiatan sistematis berarti bahwa evaluasi program dilaksanakan melalui prosedur yang tertib berdasarkan kaidah-kaidah ilmiah. Data dan informasi adalah yang dikumpulkan sebagai bahan pertimbangan pembuat keputusan. Pengambilan keputusan terhadap program berarti bahwa data yang disajikan akan bernilai apabila menjadi masukan untuk pengambilan keputusan yang akan diambil terhadap program.

Tujuan evaluasi Program adalah untuk mengetahui pencapaian tujuan program dengan langkah mengetahui keterlaksanaan kegiatan program tersebut. Ada macam

\footnotetext{
${ }^{10}$ Hasan, Hamid. Evaluasi Kurikulum. (Bandung: Remaja Rosdakarya, 2009), h.33.

${ }^{11}$ Djali dan Puji Mulyono, Pengukuran Dalam Bidang Pendidikan, (Jakarta: Grasindo, 2008), h.1. 1984), h. 10.

${ }^{12}$ Leonard Rutman, Evaluation Research Methods: A Basic Guide (London: Sage Publications,

${ }^{13}$ Laura Langbein dan Claire L. Felbinger, Public Program Evaluation: A Statical Guide (New York: M.B. Sharpe Inc., 2006), h. 3.
} 
tujuan evaluasi program, yaitu tujuan umum dan tujuan khusus. Tujuan umum diarahkan pada masing-masing komponen.

Mark, Henry dan Julhanes mengemukakan bahwa ada 4 tujuan evaluasi, yaitu : 1) penilaian manfaat dan kebaikan; 2) kekeliruan dan pemenuhan; 3) perbaikan program dan evaluasi; dan 4) pengembangan dan pengetahuan. ${ }^{14}$

Dalam arti luas, tujuan dan fungsi evaluasi dalam pendidikan adalah sebagai penyedia informasi tentang : (a) penguasaan pengetahuan, nilai, sikap, dan keterampilan untuk perbaikan pendidikan; (b) pengendalian mutu pendidikan dan pembelajaran; (c) pengambilan keputusan tentang peserta belajar; (d) akuntabilitas untuk peserta belajar dan publik; dan (e) regulasi admininstratif. ${ }^{15}$

Di sekolah atau lembaga pendidikan nonformal lainnya, evaluasi pendidikan merupakan salah satu variabel dalam proses pendidikan yang dapat memberikan umpan balik (feedback) bagi penyempurnaan pendidikan untuk masa berikutnya, baik yang berhubungan dengan proses pelaksanaan maupun yang dicapai sebagai salah satu variabel yang menentukan.

Informasi yang diperoleh dari kegiatan evaluasi sangat bermanfaat bagi pengambilan keputusan dan kebijakan lanjutan dari program. Wujud dari hasil evaluasi adalah sebuah rekomendasi dari evaluator untuk pengambil keputusan (decision maker). Ada empat kemungkinan kebijakan yang dapat dilakukan berdasarkan hasil dalam pelaksanaan sebuah program keputusan, yaitu ${ }^{16}$ :

1. Menghentikan program, karena dipandang bahwa program tersebut tidak manfaatnya, atau tidak dapat terlaksana sebagaimana diharapkan.

2. Merevisi program, karena ada bagian-bagian yang kurang sesuai dengan harapan (terdapat kesalahan tetapi hanya sedikit).

3. Melanjutkan program, karena pelaksanaan program menunjukan bahwa segala sesuatu sudah berjalan sesuai dengan harapan dan memberikan hasil yang bermanfaat.

4. Menyebarluaskan program (melaksanakan program di tempat-tempat lain atau mengulangi lagi program di lain waktu), karena program itu berhasil dengan baik maka sangat baik jika dilaksanakan lagi di tempat dan lain waktu.

Uraian panjang di atas dapat dimengerti bahwa evaluasi dalam suatu program termasuk bagian dari sistem pendidikan yang dilaksanakan. Tujuan utama dari evaluasi ini adalah untuk mengetahui sejauh mana efektifitas setiap unsur dalam pelaksanaan program pembelajaran bahasa Arab, baik dari aspek Antasecent, Transaction maupun outcomenya. Press, h. 11

${ }^{14}$ Misykat Malik Ibrahim, Evaluasi Program Bidang Pendidikan, (Makassar: Alauddin University

${ }^{15}$ A. Muri Yusuf, Assesmen dan Evaluasi Pendidikan, (Jakarta : Kencana, 2017), h. 23.

${ }^{16}$ Elis Ratnawulan, Evaluasi Pembelajaran, (Bandung: Pustaka Setia, 2015), h.21-22. 


\section{B. Model Evaluasi Countenance Stake}

Model Countenance Stake adalah model evaluasi yang dikembangkan Stake dalam tulisannya Stake tidak memberikan nama khusus terhadap model ini. Nama Countenance digunakan disini disesuaikan dengan judul artikel yang ditulis Stake walaupun pengertian countenance itu sendiri memiliki makna ambiguous. Dalam suatu pengertian ini countenance adalah keseluruhan, sedang dalam pengertian yang lain kata tersebut bermakna sesuatu yang disenangi (favorable). ${ }^{17}$

Stake mendasarkan modelnya pada evaluasi formal, evaluasi formal adalah yang dilakukan oleh pihak luar, yang tidak terlibat dengan evaluan. Lebih lanjut model ini dikembangkan atas keyakinan bahwa suatu evaluasi haruslah memberikan deskripsi dan pertimbangan sepenuhnya tentang evaluan. ${ }^{18}$

Model Countenance Stake terdiri atas dua matriks. Matriks pertama dinamakan matriks deskripsi, dan matriks kedua dinamakan matriks pertimbangan. Setiap matriks terdiri dari dua kategori dan tiga bagian. Matriks deskripsi terdiri atas kategori rencana (intent) dan observasi. Matriks pertimbangan terdiri atas kategori standar dan pertimbangan. ${ }^{19}$ Dalam evaluasi ini terdapat tiga fokus penting yang didasarkan pada pikiran Stake, bahwa suatu evaluasi formal harus memberikan perhatian terhadap keadaan sebelum suatu kegiatan kelas berlangsung ketika kegiatan berlangsung, dan menghubungkannya dengan berbagai bentuk hasil belajar. Pikiran ini diterjemahkan dalam istilah anteseden, transaksi, hasil. Antaseden adalah keadaan sebelum, transaksi adalah proses, hasil adalah kemampuan yang diperoleh peserta didik. ${ }^{20}$

Pemaparan di atas menjelaskan bahwa model Countenance Stake mempunyai dua matriks, yaitu : matriks deskripsi dan matriks pertimbangan, dan kedua matriks tersebut mempunyai tiga fokus antecedent, persiapan program sebelum berlangsung, transaction, pelakasanan program berlangsung dan outcome, hasil dari suatu program. Secara keseluruhan model ini digambarkan sebagai berikut :

${ }^{17}$ S. Hamid Hasan, Evaluasi Kurikulum, (Bandung: Remaja Rosdakarya, 2008), h.206.

${ }^{18}$ S. Hamid Hasan, Evaluasi Kurikulum, h.207.

${ }^{19}$ Etty Jaskarti, "Penerapan Model Countenance Stake dalam Evaluasi Implementasi KTSP Fisika di SMA: Studi Evaluatif pada Guru Fisika SMA Alumni Diklat Berjenjang di P4TK IPA Bandung”, Disertasi Program Doktor: Program Studi Pengembangan Kurikulum Universitas Pendidikan Indonesia Bandung 2013, h.145.

${ }^{20}$ S. Hamid Hasan, Evaluasi Kurikulum, h.208. 


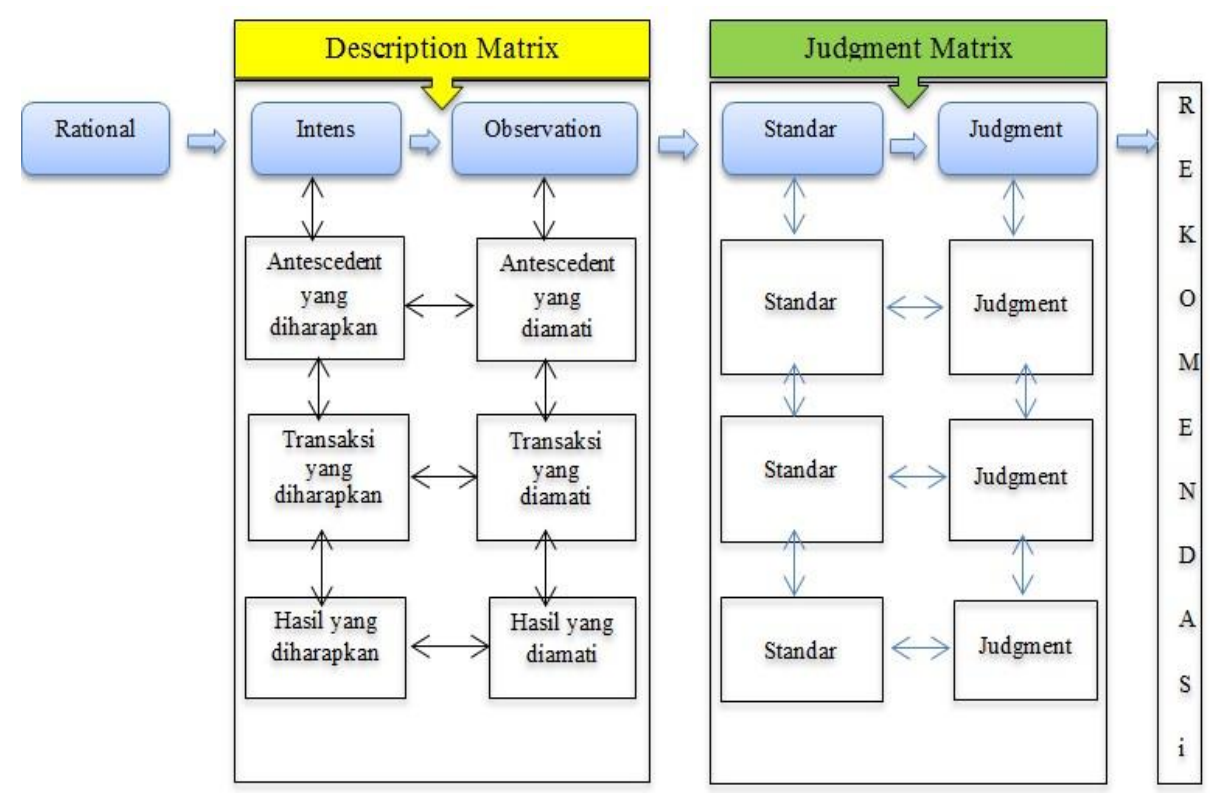

\section{JENIS PENELITIAN}

Jenis Penelitian ini merupakan evaluasi program dengan pendekatan kualitatif deskriptif, dalam penelitian ini penulis menilai tingkat mutu dan kondisi sistem pembelajaran bahasa Arab di Pondok pesantren Darussalam Liabuku Bau Bau, Untuk memperoleh data tersebut, digunakan tiga teknik pengumpulan data, yaitu observasi, wawancara dan dokumentasi. Setelah pengumpulan data maka proses selanjutnya dilakukan pengolahan data melalui tiga tahapan, yaitu : 1) reduksi data (data reduction), 2) display data (data display), 3) dan penarikan kesimpulan/verifikasi.

Lokasi penelitian dilaksanakan di Pondok Modern Darrusalam Liabuku yang berlokasi di kota Bau Bau Sulawesi Tenggara, Pemilihan lokasi tersebut didasarkan pada pertimbangan bahwa pondok pesantren Darrusalam Liabuku adalah salah satu Pondok yang telah melaksanakan pembelajaran bahasa Arab dengan sistem Kulliyatul Muallimin al-Islamiyah.

\section{HASIL DAN PEMBAHAHASAN}

Pembelajaran bahasa Arab merupakan sebuah sistem yang terdiri dari rangkaian komponen yang saling berkaitan. Rangkaian komponen dari sistem pembelajaran bahasa Arab ini bertujuan untuk mencapai hasil yang sesuai dengan kebutuhan dan tujuan tertentu. Penulis mengevaluasi komponen-komponen sistem pembelajaran bahasa Arab berikut : Perencanaan Pembelajaran, materi pembelajaran, metode pembelajaran, pelaksanaan pembelajaran, dan hasil belajar. Evaluasi dari komponen-komponen sistem pembelajaran bahasa Arab ini disajikan dalam tiga fokus, yaitu : antaseden (Persiapan), Transaksi (Proses) dan hasil. 
Setiap fokus dievaluasi berdasarkan pada matriks countenance Stake yang meliputi rencana (intent), observasi (implementasi), standar dan pertimbangan (judgement). Selanjutnya hal itu dianalisis contingency dan congruence. Analisis contingency adalah pertimbangan evaluator terhadap keterkaitan atau keselarasan logis dan empirik antara kotak anteseden dengan transaksi dan hasil. Analisis congruence adalah pertimbangan evaluator terhadap kesesuaian antara apa yang direncanakan (intent) dengan apa terjadi dalam pelaksanaan kegiatan (observasi).

\section{A. Analisis Contingency dan Analisis Congruence}

1. Antaseden (Persiapan)

Antaseden (Persiapan) dalam konteks penelitian ini adalah perencanaan pembelajaran bahasa Arab di Pondok Pesantren Darussalam Liabuku Bau Bau yang mencakup Rencana Pelaksanaan Pembelajaran (RPP) atau I'dõd al-tadrīs.

a. Rencana

Pembelajaran bahasa Arab di Pondok Pesantren Darussalam Liabuku Bau Bau menerapkan sistem pengajaran terpisah. Berdasarkan data dokumentasi yang didapat penulis, kelompok mata pelajaran bahasa Arab yang diajarkan di Kulliyatul Muallimin Al-Islamiyyah Pondok Pesantren Darussalam Liabuku terdiri beberapa mata pelajaran, yaitu: ${ }^{21}$

Tabel. 4.3.

Kelompok mata pelajaran Bahasa Arab

\begin{tabular}{|c|c|c|}
\hline No & Mata Pelajaran & Keterangan \\
\hline 1 & Nahwu & Kaidah Bahasa Arab \\
\hline 2 & Șarfu & Kaidah Bahasa Arab \\
\hline 3 & $\operatorname{Insy} \tilde{\alpha}$ & 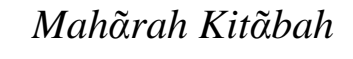 \\
\hline 4 & Mutõla'ah & 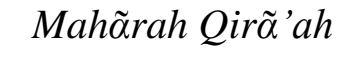 \\
\hline 5 & Imla' & 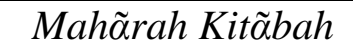 \\
\hline
\end{tabular}

Diantara banyak pelajaran bahasa Arab di Pondok Pesantren Darussalam Liabuku, tidak semua mata pelajaran yang akan dianalisis oleh penulis, penulis mengambil sebagian mata pelajaran yang akan dianalisis, yaitu nahwu, Sarfu, Imla', insy $\tilde{\alpha}$ dan Mutõla'ah. Beberapa mata pelajaran yang diteliti tersebut, merupakan materi pokok dalam pembelajaran bahasa Arab yang telah mewakili mata pelajaran kaidah bahasa Arab

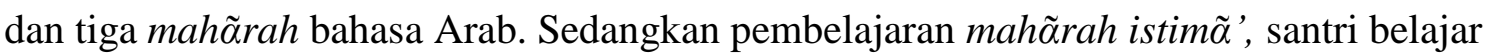
langsung dalam setiap proses pembelajaran. Seperti dijelaskan sebelumnya bahwa proses pembelajaran bahasa Arab yang ada MA Kulliyatul Muallimin Al-Islamiyah pondok

${ }^{21}$ Arsyid Saleh, S.Pd.,M.Pd, Direktur Kulliyatul Muallimin al-Islamiyah KMI Pondok Pesantren Darussalam Liabuku Bau-Bau, wawancara pada tanggal 15 Agustus 2019 Pukul. 09.30 WITA 
pesantren Darussalam Liabuku kota Bau Bau menggunakan bahasa pengantar bahasa

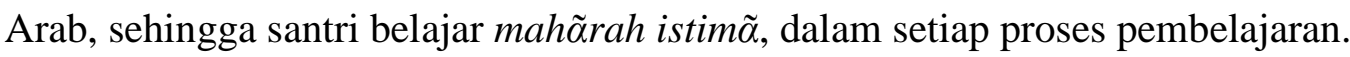

Secara umum tujuan pembelajaran bahasa Arab di MA Kulliyatul Muallimin AlIslamiyah Pondok Pesantren Darussalam Liabuku Kota Bau Bau adalah santri memiliki kompetensi Bahasa Arab baik secara teoritis maupun praktis. ${ }^{22}$ Sedangkan secara spesifik tujuan pembelajaran bahasa Arab dapat dilihat dari setiap mata pelajaran bahasa Arab sebagai berikut: ${ }^{23}$

1. Nahwu bertujuan agar santri dapat mengetahui jabatan kata dalam kalimat dan bentuk huruf/harakat terakhir dari suatu kata.

2. Mutõla'ah bertujuan untuk melatih santri dalam membaca teks Arab dan memahami apa yang dibaca.

3. Insya bertujuan agar santri dapat mengemukakan gagasan pikirannya dalam bentuk karya tulis.

4. Sarfu bertujuan agar siswa dapat mengetahui bentuk kalimat Arab dan hal ihwalnya.

5. Imla' bertujuan untuk membekali siswa dalam keterampilan menulis huruf hija'iyyah dalam bentuk kata ataupun kalimat.

Untuk mencapai tujuan-tujuan pembelajaran tersebut, dalam mempersiapkan pembelajaran bahasa Arab, guru melakukan perencanaan pembelajaran dengan Rencana Pelaksanaan Pembelajaran (RPP) atau i'dõd al-Tadrīs bahasa Arab yang di MA Kuliyatul Muallimin Al-Islamiyah Pondok Pesantren Darussalam Liabuku Kota Bau Bau menggunakan bahasa Arab sebagai bahasa pengantarnya, ${ }^{24}$ dengan komponen-komponen sebagai berikut : identitas guru, identitas mata pelajaran, alokasi waktu, kelas/semester, tujuan pembelajaran, sumber belajar, langkah-langkah pembelajaran dilakukan melalui tahapan pendahuluan, inti dan penutup, dan evaluasi didalamnya tertulis lengkap baik dialog maupun kegiatan yang dilakukan guru selama kegiatan yang dilakukan guru selama kegiatan belajar mengajar. ${ }^{25}$

I'dõd al-Tadrīs bahasa Arab di MA Kulliyatul Muallimin al-Islamiyah Pondok Pesantren Darussalam Liabuku dibuat secara mandiri oleh guru pengajar, kemudian I'd ãd al-Tadrīs tersebut dikoreksi oleh pimpinan Pondok atau Direktur KMI Kuliyatul Muallimin al-Islamiyah pesantren Darussalam Liabuku Bau Bau.

\footnotetext{
${ }^{22}$ Ahmad Karim, S.Pd.I.,M.Pd, Pimpinan Pondok Pesantren Darussalam Liabuku kota Bau Bau, wawancara, Pada 25 Tanggal 25 Agustus 2019

${ }^{23}$ Zaki, S.Pd.I.,M.Pd, Guru bahasa Arab Kulliyatul Muallimin Al-Islamiyah Pondok Pesantren Darussalam Liabuku Kota Bau Bau, wawancara pada selasa Tanggal 27 Agustus 2019

${ }^{24}$ Zulfian, S.H.I, Guru bahasa Arab Kulliyatul Muallimin Al-Islamiyah Pondok Pesantren Darussalam Liabuku Kota Bau Bau, wawancara Pada selasa Tanggal 27 Agustus 2019.

${ }^{25}$ Mahmud Yunus dan Muhammad Qosim Bakri, al-Tarbiyah al-Amaliyah fi al-Tadris, (Ponorogo : KMI Gontor, tt), h.61.
} 
b. Observasi (pelaksanaan)

Adapun dalam observasi penulis terhadap I'dõd al-Tadrīs menunjukan bahwa setiap guru sudah membuat I'dõd al-Tadrīs, hal ini ditunjukan dari setiap guru yang memiliki I'd ̃̃d al-Tadrīs bahasa Arab, namun masih penulis menemukan beberapa I'd $\tilde{\alpha} d$ al-Tadrīs yang belum disahkan oleh direktur Kulliyatul Muallimin al-Islamiyah Pondok Pesantren Darussalam Liabuku Bau-Bau.

Dari observasi penulis, I'dãd al-Tadrīs yang dibuat guru-guru di MA Kulliyatul Muallimin Al-Islamiyah Pondok Pesantren Darussalam Liabuku sudah memenuhi komponen-komponen I'd ̃̃d al-Tadrīs berikut : identitas guru, identitas mata pelajaran, alokasi waktu, kelas/semeseter, tujuan pembelajaran, sumber belajar, langkah-langkah pembelajaran dilakukan melalui tahapan pendahuluan, inti dan penutup, dan evaluasi, didalamnya juga sudah tertulis lengkap kegiatan yang dilakukan guru selama kegiatan belajar mengajar.

Penulis cermati pembuatan I'd ̃̃d al-Tadrīs di MA Kulliyatul Muallimin AlIslamiyah Pondok Pesantren Darussalam Liabuku Bau Bau sudah memenuhi kriteria penyusunan perencanaan pembelajaran, baik signifikansi dari I'd $\tilde{\alpha} d$ al-Tadrīs yang dibuat terlihat dari efektifitas pembelajaran yang berlangsung, I'dõd al-Tadrīs juga sudah relevan dengan kurikulum yang berlaku di MA Kulliyatul Muallimin al-Islamiyah, dimana kurikulum yang berlaku di MA Kulliyatul Muallimin al-Islamiyah pembelajarannya mengacu pada Gontor, selain itu I'd ̃̃d al-Tadrīs yang dibuat sudah relevan dalam membantu santri mencapai tujuan pembelajaran. I'dõ d al-Tadrīs yang dibuat guru sudah menunjukan kepastian, hal ini terlihat dari I'dõ d al-Tadrīs yang dibuat alternatif-alternatif yang bisa dipilih, tetapi berisi langkah-langkah pasti yang dilakukan secara sistematis, dan kesederhanaan sehingga mudah diimplementasikan, selain itu I'd $\tilde{\alpha} d$ al-Tadrīs yang ada tidak bersifat kaku dapat diimplementasikan dalam berbagai kondisi tanpa syarat-syarat tertentu.

c. Standar

Standar dan acuan I'dõd al-Tadrīs MA Kulliuyatul Mu'allimin Al-Islamiyah Pondok Pesantren Liabuku Bau Bau adalah I'dõd al-Tadrīs yang ada dikitab alTarbawiyah al-Amaliyah fi al-Tadris karya Mahmud Yunus dan Muhammad Qosim Bakri KMI Gontor. ${ }^{26}$

I'dõd al-Tadrīs dalam al-Tarbiyah al- 'Amaliyah fi al-Tadris memiliki komponenkomponen sebagai berikut : identitas guru, identitas mata pelajaran, alokasi waktu, kelas/semester, tujuan pembelajaran, materi pembelajaran, media pembelajaran, langkahlangkah pembelajaran dilakukan melalui tahapan pendahuluan, inti dan penutup, dan

${ }^{26}$ Ramsul, S.Pd.,M.Pd, Guru bahasa Arab Kulliyatul Muallimin al-Islamiyah pondok pesantren Darussalam Liabuku Bau Bau, wawancara, pada Rabu tanggal 28 Agustus 2019 
evaluasi, didalamnya juga sudah tertulis lengkap kegiatan yang dilakukan guru selama kegiatan belajar mengajar. ${ }^{27}$

d. Pertimbangan

Komponen yang dievaluasi pada anteseden ini adalah perencanaan pembelajaran bahasa Arab yang terangkum dalam I'dõd al-Tadrīs yang dibuat oleh guru bahasa Arab di MA Kulliyatul Muallimin al-Islamiyah Pondok Pesantren Darussalam Liabuku Bau Bau yang menjadi sasaran standar al-Tarbiyah al-Amaliyah fi al-Tadris. Berikut ini disajikan matriks komponen antaseden pada tabel :

\begin{tabular}{|c|c|c|c|}
\hline \multicolumn{2}{|c|}{ Matriks deskripsi } & \multicolumn{2}{|c|}{ Matriks pertimbangan } \\
\hline Rencana & Observasi & Standar & Pertimbangan \\
\hline $\begin{array}{l}\text { Guru bahasa Arab } \\
\text { membuat I'd ̃̃d al- } \\
\text { Tadrīs } \\
\text { berdasarkan al- } \\
\text { Tarbiyah al- } \\
\text { Amaliyah fi al- } \\
\text { Tadrīs }\end{array}$ & $\begin{array}{l}\text { Guru bahasa } \\
\text { Arab sudah } \\
\text { membuat I'dõd } \\
\text { al-Tadrīs } \\
\text { berdasarkan al- } \\
\text { Amaliyah fi al- } \\
\text { Tadris }\end{array}$ & $\begin{array}{l}\text { Komponen I'dõd al- } \\
\text { Tadrīs berdasarkan } \\
\text { standar al-Tarbiyah } \\
\text { al-amaliyah fi' al- } \\
\text { Tadrīs meliputi: 1) } \\
\text { identitas mata } \\
\text { pelajaran, 2) Tujuan } \\
\text { pembelajaran, 3) } \\
\text { Materi pembelajaran, } \\
\text { 4) Jenis Metode } \\
\text { pembelajaran, 5) } \\
\text { langkah langkah } \\
\text { pembelajaran yang } \\
\text { dilakukan melalui } \\
\text { tahapan pendahuluan, } \\
\text { inti dan penutup, 6) } \\
\text { evaluasi. }\end{array}$ & $\begin{array}{l}\text { Aktualisasi } \\
\text { ketercapaian } \\
\text { I'dõd al-Tadrīs } \\
\text { yang dibuat guru } \\
\text { bahasa Arab } \\
\text { termasuk dalam } \\
\text { kategori baik, } \\
\text { yaitu sesuai } \\
\text { dengan kriteria } \\
\text { yang telah } \\
\text { ditetapkan dalam } \\
\text { standar al- } \\
\text { Tarbiyah al- } \\
\text { Amaliyah fi al- } \\
\text { Tadrīs. }\end{array}$ \\
\hline
\end{tabular}

Berdasarkan tabel diatas, I'd ̃̃d al-Tadrīs yang dibuat guru bahasa Arab di MA Kulliyatul Muallimin al-Islamiyah Pondok Pesantren Darussalam Liabuku Bau Bau termasuk dalam kategori baik. Adanya kesesuaian rencana dengan observasi pada matriks deskripsi menunjukan sudah adanya kesesuaian antara ketersediaan I'dõd al-Tadrīs yang

${ }^{27}$ Mahmud Yunus dan Muhammad Qosim Bakri, al-Tarbiyah al-Amaliyah, h.61. 
dibuat guru bahasa Arab dengan standar yang ada di tarbiyah al-amaliyah. Namun hal ini masih belum maksimal. Salah satu faktor yang mempengaruhi belum maksimalnya capaian tersebut meliputi latar belakang guru bahasa Arab, belum semua guru pengajar bahasa Arab memiliki kualifikasi dalam bidang bahasa Arab. Hal ini menyebabkan kurangnya kesiapan guru dalam mempersiapkan pembelajaran di kelas. Kurangnya kesiapan guru dalam mempersiapkan pembelajaran yang kurang bervariasi sehingga pelaksanaan pembelajaran menjadi monoton. ${ }^{28}$

\section{KESIMPULAN DAN REKOMENDASI}

A. Kesimpulan

Setelah menguraikan bagaimana evaluasi program sistem pembelajaran bahasa Arab MA Kulliyatul Mu'allimin al-Islamiyah pondok pesantren Darussalam Liabuku Bau Bau, antaseden, transaction dan outcome ,bahwa secara umum program pembelajaran telah berjalan dengan baik. Kesimpulan tiap aspek yaitu :

1. Antaseden (persiapan)

Hasil evaluasi terhadap sistem pembelajaran bahasa Arab di pondok pesantren Darussalam Liabuku Bau Bau sudah sesuai dengan standar. Dalam konteks adalah perencanaan pembelajaran bahasa Arab di Pondok Pesantren Darussalam Liabuku Bau Bau yang mencakup Rencana Pelaksanaan Pembelajaran (RPP) atau I'dõd al-tadrīs yang sudah ditanda tangani oleh Direktur KMI atau pimpinan pondok pesantren.

\section{Transaction}

Hasil evaluasi terhadap transaction Guru melakukan perencanaan pembelajaran dengan Rencana Pelaksanaan Pembelajaran (RPP) atau i'd ̃̃d al-Tadrīs bahasa Arab yang di MA Kuliyatul Muallimin Al-Islamiyah Pondok Pesantren Darussalam Liabuku Kota Bau Bau masih butuh perbaikan menggunakan bahasa Arab sebagai bahasa pengantarnya sebagai standar al-Tarbiyah al-Amaliyah fi al-Tadris.

\section{OutCome}

Pencapaian hasil sistem pembelajaran bahasa Arab di MA Kulliyatul Mua'llimin al-Islamiyah dilihat dari hasil evaluasi komponen anteseden, proses dan hasil menunjukkan bahwa komponen-komponen sistem pembelajaran bahasa Arab sudah dapat mencapai tujuan pembelajaran. Pencapaian tujuan pembelajaran ini ditujukkan dengan terbentuknya santri menguasai bahasa Arab reseptif (mahõrah al-istima' dan

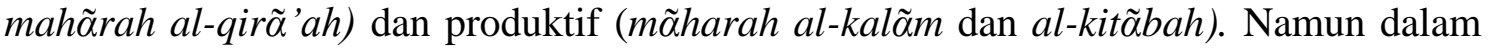
penguasaan bahasa Arab ini santri masih belum lepas dari permasalahan linguistik bahasa Arab sehingga masih terjadi kesalahan berbahasa, seperti adanya interferensi bahasa dalam percakapan santri..

${ }^{28}$ Yusril, Santri Kelas V Asal Namlea Maluku MA Kulliyatul Muallimin al-Islamiyah pondok pesantren Darussalam Liabuku Bau Bau, Wawancara, pada Kamis tanggal 29 Agustus 2019. 
B. Rekomendasi

Berdasarkan hasil penelitian dan pembahasan pada BAB IV, maka peneliti merekomendasikan pimpinan pondok Pesantren Darussalam dan Direktur KMI perlu dilanjutkan dengan beberapa perbaikan sebagai berikut :

1. Dalam tujuan pembelajaran bahasa Arab, guru seharusnya menjelaskan perbedaan karakteristik antara bahasa Arab dan bahasa Indonesia, hal ini untuk memudahkan santri belajar bahasa Arab dan meminimalkan permasalahan linguistik dalam pembelajaran bahasa Arab.

2. Pondok Pesantren Darussalam Liabuku Bau-Bau menyediakan fasilitas kegiatan kebahasaan, hal ini istima' dari native bahasa Arab agar santri lebih mengetahui perbedaan lahjah dan karakteristik bahasa Arab yang digunakan native bahasa tersebut dengan bahasa Indonesia.

\section{DAFTAR PUSTAKA}

Andri Lundeto. (2012) Sistem Pendidikan Pesantren : Analisis Masalah dan Solusi, Malang : UIN Malang.

Amin Haedani, (2010) Masa Depan Pesantren : Tantangan Modernitas dan Tantangan Komplesitas Global, Jakarta: IRD Press.

Asrori, Imam, dkk. (2012) Evaluasi Dalam Pembelajaran Bahasa Arab, Malang: Misykat Indonesia.

A.Muri Yusuf. (2017) Assesmen dan Evaluasi Pendidikan, Jakarta : Kencana.

Djali dan Puji Mulyono, (2008) Pengukuran Dalam Bidang Pendidikan, Jakarta: Grasindo.

Etty Jaskarti, (2013 )"Penerapan Model Countenance Stake dalam Evaluasi Implementasi KTSP Fisika di SMA: Studi Evaluatif pada Guru Fisika SMA Alumni Diklat Berjenjang di P4TK IPA Bandung”, Disertasi Program Doktor: Program Studi Pengembangan Kurikulum Universitas Pendidikan Indonesia Bandung.

Elis Ratnawulan, (2015). Evaluasi Pembelajaran, Bandung: Pustaka Setia.

Huey-Tsyh Chen.( 2005) Practical Program Evaluation: Assessing and Improving Planning, Implementation and Effectiveness (London: Sage Publications.

Hasan, Hamid. (2009) . Evaluasi Kurikulum. Bandung: Remaja Rosdakarya.

Hermawan, A.H dkk. (2010) Pengembangan Kurikulum dan Pembelajaran (Jakarta: Direktorat Pendidikan Islam. 
Leonard Rutman. (1984)Evaluation Research Methods: A Basic Guide, London: Sage Publications.

Laura Langbein dan Claire L. Felbinger. (2006) Public Program Evaluation: A Statical Guide (New York: M.B. Sharpe Inc.

Lorens Bagus, (1996). Kamus Filsafat Jakarta: Gramedia.

Kemententrian Pendidikan dan Kebudayaan, (1993)Kamus Besar Bahasa Indonesia, (Cet. II; Jakarta : Balai Pustaka.

Purwanto dan Suparman. (2017) Evaluasi Program, dalam Rusdy Ananda dan Tien Rafida, Pengantar Evaluasi Program Pendidikan (Medan : Perdana Publishing.

Slamto. (2010) Belajar dan Faktor-faktor yang Mempengaruhinya, (Jakarta : Rineka Cipta.

Sulistyorini. (2009) Evaluasi Pendidikan, Yogyakarta: Teras.

Suharsismi Arikunto. (2012) Dasar-dasar Evaluasi Pendidikan, Jakarta : PT. Bumi Aksara.

Syamsuddin Asyrofi. (2016)Metodologi Pengajaran Bahasa Arab : Konsep dan Implementasinya, Yogyakarta: Penertbit Tombak, .

Suja'I. (2008). Inovasi Pembelajaran Bahasa Arab, Semarang : Wali Songo Press.

Suharsimi Arikunto, Cepi Safruddin Jabar. (2009) Evaluasi Program Pendidikan, (Jakarta: PT. Bumi Aksara.

Suke Silverius, (1991). Evaluasi Hasil Belajar dan Umpan Balik, Jakarta : Grasindo.

S. Hamid Hasan, (2008). Evaluasi Kurikulum, (Bandung: Remaja Rosdakarya,

Salamoen S. (1999).Pendekatan Sistem Dalam Manajemen, Jakarta: LAN-RI.

Wina Sanjaya. (2011) Strategi Pembelajaran Berorientasi Standar Proses Pendidikan, (Cet. VIII, Jakarta : Kencana)

Wina Sanjaya. (2008) Perencanaan dan Desain Sistem Pembelajaran, Jakarta : Kencana. 